\title{
Z HISTORII BADAŃ STANOWISK WCZESNEJ KULTURY CZERNIACHOWSKIEJ
}

\section{HISTORY OF RESEARCH ON THE SITES OF EARLY CHERNYAKHOV CULTURE}

\author{
Maksym Stroceń \\ Instytut Archeologii Narodowej Akademii Nauk Ukrainy \\ Al. Heroiv Stalingrada 12, 04-210 Kijów, Ukraine
}

РЕЗЮМЕ. В статті подана інформація про дослідження раннього етапу черняхівської культури. Дослідники цей етап називають Ружичанською фазою (230-270 pp. н. е). Виокремлений він 3 допомогою речей, які дають вузьку хронологічну дату (фібули, гребені, намистини, кубки та інші). Інформацію про даний період було отримано в результаті дослідження могильників, рідше з поселень.

ABSTRACT. This article provides information about the study of the early stage of Chernyakhov culture. Researchers call this stage Ruzhychanska phase (230-270 AD). Period is distinguished on the basis of chronological indicators (fibulas, combs, cups, beads and more). Information on this phase comes mainly from excavations of the cemeteries, rarely - settlements.

Dla rozumienia dowolnej kultury archeologicznej ważne są badania nad jej wczesnym etapem. Kultura czerniachowska nie jest w tym względzie wyjątkiem. Celem niniejszej publikacji jest analiza historii badań wczesnego etapu tej kultury, któremu jak dotąd nie poświęcono odrębnych studiów. Rozpatrywano go tylko w kontekście badań nad całą kulturą czerniachowską. Do tego etapu zalicza się tzw. fazę różyczańską, datowaną na lata 230-270 n.e. ${ }^{1}$.

W latach 1929-1930 prowadzone były badania wykopaliskowe cmentarzyska we wsi Prywilne nad dolnym Dnieprem ${ }^{2}$. Przed drugą wojną światową w rejonie tym odkryto jeszcze jedną nekropolię kultury czerniachowskiej we wsi No-

\footnotetext{
${ }^{1}$ Гороховський 1988, 42-43.

${ }^{2}$ Кухаренко 1955, 125-152.
} 
wo-Oleksandriwki nad dolnym Dnieprem. Badania były prowadzone głównie w czasie wojny ${ }^{3}$.

W trakcie wykopalisk w Krynyczkach w obwodzie odesskim w latach 1957-1958 S. Hamczenko odnalazł jeszcze jeden pochówek z wczesnego etapu ${ }^{4}$. Pod koniec lat 50. i na początku lat 60. I. Wynokur i M. Ostrowski zarejestrowali wczesne zespoły czerniachowskie na cmenatrzysku Czesniwski Rakowiec w obwodzie tarnopolskim ${ }^{5}$. W tym czasie rozpoczęły się również badania cmentarzyska Ryżiwka w obwodzie czerkaskim, położonym nad rzeką Jatrań, które trwały do 1967 r. .

W latach 1961-1964 W. Pietrow i N. Krawczenko badali cmentarzysko Kosanowo w obwodzie winnickim ${ }^{7}$. Zarówno na stanowisku Kosanowo, jak i Czesniwski Rakowiec odkryte zostały dwa pochówki, należące do wczesnego etapu. Nekropolia w Różyczance w obwodzie chmielnickim, badana wykopaliskowo przez I. Wynokura w latach 1964-1966, ma dosyć ważne znaczenie dla studiów nad wczesnym etapem kultury czerniachowskiej. Odkryto w niej 6 pochówków ${ }^{8}$.

Jednakże najbardziej obiecującym obecnie stanowiskiem jest cmentarzysko Czernielów Ruski, na którym odkryto 18 pochówków omawianego etapu. Stanowisko było badane przez I. Heretę w latach 1973-20009.

Mimo że większość wczesnych zespołów odkryto na cmentarzyskach kultury czerniachowskiej w latach 50. i 60., autorzy badań praktycznie nie próbowali wydzielać wczesnego horyzontu. Pewne spostrzeżenia, dotyczące różnic między wczesnymi i późnymi pochówkami, zostały jednak poczynione ${ }^{10}$. Horyzonty były wydzielone dopiero przez badaczy, którzy szczegółowo zajmowali się chronologią. Ich badania dały możliwość określenia zasięgu terytorialnego wczesnych stanowisk. Obejmuje on dorzecze Dniestru, Bohu i Dniepru.

W 1950 r. na stanowiskach kultury czerniachowskiej po raz pierwszy zarejestrowano domostwa, które zaliczono do wczesnego etapu. Jednymi z pierwszych były domostwa ze stan. Czerepin w obwodzie lwowskim. Osada ta została odkryta przez A. Schneidera, a w latach 1954-1956 stacjonarne badania prowadziła tam ekspedycja Instytutu Nauk Społecznych Akademii Nauk Ukraińskiej Socjalistycznej Republiki Radzieckiej (obecnie: Instytut Ukrainoznawstwa Narodowej Akademii Nauk Ukrainy) pod kierownictwem W. Barana. Zarejestrowano 8 domostw i 14 jam gospodarczych z ceramiką wykonaną ręcznie i na kole garncarskim, z narzędziami z żelaza, zapinkami i innymi przedmiotami, charakterystycznymi dla kultury czer-

\footnotetext{
${ }^{3}$ Сымонович 1975, 203-212.

${ }^{4}$ Сымонович 1960, 239-252.

${ }^{5}$ Винокур, Островський 1967, 144-159.

${ }^{6}$ Кропоткин 1972, 264-269.

${ }^{7}$ Кравченко 1967, 77-135.

${ }^{8}$ Винокур 1979, 112-135.

${ }^{9}$ Герета 1995, 144-163.

${ }^{10}$ Герета 1991, 30.
} 
niachowskiej $^{11}$. W latach 1958-1961 W. Baran odkrył domostwa z wczesnego etapu na stan. Ripniw w obwodzie lwowskim ${ }^{12}$.

Osada Lepesiwka (rejon biłohirski, obwód chmielnicki) została odkryta w 1905 r. przez J. Jarockiego; stanowisko badano w latach 1957-1959 w ramach ekspedycji dniestrzańsko-wołyńskiej, prowadzonej przez M. Tychanową. Jedno ze zbadanych wykopaliskowo domostw funkcjonowało we wczesnym etapie kultury czerniachowskiej $^{13}$.

Pierwsza próba wyodrębnienia wczesnego etapu tej kultury miała miejsce na początku lat 80. Próba ta, choć - jak zaznaczył jeden z jej autorów, M. Szczukin nie do końca udana, polegała na podziale materiałów z cmentarzyska Dănceni na etapy chronologiczne $\mathrm{z}$ zastosowaniem metody korelacyjnej ${ }^{14}$. Kolejne były już bardziej udane. Jednakże dotyczyły one wyłącznie konstruowania schematów chronologicznych. Funkcjonujące obecnie opracowania, poświęcone chronologii kultury czerniachowskiej, można umownie podzielić na trzy grupy:

- prace poświęcone chronologii całej kultury;

- prace dotyczące datowania oddzielnych okresów, np. badania I. Hawrytuchina nad chronologią okresu huńskiego ${ }^{15}$;

- prace poświęcone datowaniom odrębnych kategorii znalezisk: zapinek ${ }^{16}$, grzebieni $^{17}$, paciorków szklanych ${ }^{18} \mathrm{i}$ in.

Warto krótko scharakteryzować pierwszą grupę prac, skupiając się na kwestii datowania wczesnego etapu. Przede wszystkim należy wymienić badania J. Gorochowskiego $^{19}$, I. Bażana oraz O. Hej ${ }^{20}$, O. Szarowa ${ }^{21}$.

J. Gorochowski przeanalizował materiały z 45 cmentarzysk. Przede wszystkim wziął pod uwagę zespoły zwarte z przynajmniej dwoma datownikami - importami metalowymi, szkłem, ceramiką, zapinkami, sprzączkami i innymi elementami pasów, grzebieniami kościanymi i żelaznymi. W niektórych przypadkach autor brał pod uwagę również zespoły z jednym tylko datownikiem. Miało to miejsce jedynie wtedy, gdy można było go dokładnie odnieść do chronologii bezwzględnej. Zalicza się tu m.in. importy rzymskie czy unikatowe typy ozdób. W celu określenia typów i wariantów artefaktów datujących badacz wykorzystał funkcjonujące klasyfikacje

\footnotetext{
${ }^{11}$ Баран 1961, 25-51.

${ }^{12}$ Баран 1964, 213-250.

${ }^{13}$ Тиханова 1963, 182-183; Щукин 1999, 12.

${ }^{14}$ Щукин, Щербакова 1986, 177-219.

${ }^{15}$ Гавритухин 1999, 48-86.

${ }^{16}$ Амброз 1966, 113.

${ }^{17}$ Никитина, 1969, 147-159; Шишкін 2002, 244-246.

${ }^{18}$ Алексеева 1982, 175.

${ }^{19}$ Гороховский 1985, 34- 45.

${ }^{20}$ Бажан, Гей 1992, 157-182.

${ }^{21}$ Шаров 1992, 158-207.
} 
H. Nikitinej, G. Rau, G. Eggersa, O. Almgrena, A. Ambrosa, M. Schulze, E. Meyera. Ponadto Gorochowski opracował szczegółową klasyfikację najliczniejszej podgrupy ozdób czerniachowskich - dwuczęściowych wygiętych zapinek z wąską, podwiniętą nóżką i z kolankiem (z przodu lub pośrodku kabłąka) lub z miękko, asymetrycznie wygiętym kabłąkiem. Uszczegółowił on również typologię i datowanie jednoczęściowych sprzączek z metali kolorowych i żelaza. Zbiory paciorków posłużyły jako pomocnicze wskaźniki. Na podstawie analizy wspomnianych materiałów badacz ten wydzielił 5 faz rozwojowych kultury czerniachowskiej.

Najwcześniejsza jest faza różyczańska, do której zaliczono zespoły z importami rzymskimi - przede wszystkim z unikatowymi wyrobami metalowymi, legionową emaliowaną blaszką, elementem końskiej uprzęży, kałamarzem, szklanymi pucharkami na wysokiej nóżce (typ Eggers 189) oraz o zbliżonej formie, kulistymi czarkami szklanymi (typ Eggers 216), fibulami grupy VII Almgrena, a także zapinkami z podwiniętą nóżką serii A: warianty A1 i A2. Do fazy tej zaliczane są również sprzączki pewnego typu. Dolną granicę fazy datują zapinki serii A, mające analogie w krajach bałtyckich i na Krymie, znalezione w zespołach z monetami, datowanymi na lata 222-235 n.e., 238-244 n.e., 244-249 n.e. W mniejszym stopniu granicę tę wyznaczają szklane czarki. W ogólnym ujęciu faza ta datowana jest na lata $230-270$ n.e. Odnoszą się do niej pojedyncze pochówki z cmentarzysk z prawobrzeżnej części lasostepu - Różyczanka, Kosanowo, Czesniwski Rakowiec, Krynyczki, Zawadówka, Czernielów Ruski, Romankiwci, Horodnica, Toki, Żurawka, Romaszki. Cały materiał pozwala ogólnie zsynchronizować pierwszą fazę kultury czerniachowskiej z fazami C1b i C2 chronologii europejskiej/okresu wpływów rzymskich.

Do drugiej (bereżańskiej) fazy zaliczane są zespoły z naczyniami metalowymi typu Eggers 62 i 82, szklanymi kubkami z ,żebrowaniem na brzuścu” lub na kolistej nóżce, brązowymi dzwoneczkami późnosarmackimi, zapinkami wariantu A3a i A4a o wyraźnych krawędziach i in., znaleziskami wyraźnie odnoszącymi się do okresu 240-270 n.e. Faza datowana jest na ostatnie trzydziestolecie III w. - pierwsze IV w. (ok. 270-330 n.e.).

Faza 1/2 (,,przejściowa”) - są to pojedyncze zespoły bez importów, z indywidualnymi typami zapinek i rzadko spotykaną sprzączką - podwójną biowalną. Fazę tę datują również dwuczęściowe zapinki z podwiniętą nóżką i wygiętym kabłąkiem, okrągłym lub romboidalnym w przekroju, zapinki z podwiniętą, rozszerzającą się nóżką II i III serii Ambrosa, zapinka Bugelknopfibeln z wąską nóżką i zaokrąglonym, gładkim korpusem typu Almgren 170. Na podstawie analogii można datować tę fazę na połowę III w. - początek IV w., głównie zaś na drugą połowę III w. ${ }^{22}$

W badaniach nad chronologią kultury czerniachowskiej I. Bażan i O. Hej przeanalizowali materiały tylko 10 cmentarzysk z obszaru prawobrzeżnego lasostepu. Wzięli pod uwagę zarówno znaleziska mniej lub bardziej wiarygodnie datowane, jak

${ }^{22}$ Гороховський 1985, 34-35, 42-46. 
i te, które można było wydatować dzięki korelacyjnej obróbce materiału. Wszystkie artefakty zostały przez autorów uznane za wyznaczniki chronologiczne. Oprócz terminu „wyznacznik chronologiczny” w pracy wykorzystano określenie „,wskaźnik synchronizacji”. Są to znaleziska spotykane w pojedynczych egzemplarzach i niewłączane do tablic korelacyjnych, lecz wyodrębnione jako wyznaczniki chronologiczne dzięki materiałom pochodzącym z innych cmentarzysk.

Datownikami w opracowaniu I. Bażana i O. Hej są więc miski, garnki, zapinki, grzebienie, sprzączki, paciorki. W opinii badaczy przedmioty znalezione w pochówku w równym stopniu datują obiekt ${ }^{23}$.

Dla każdego stanowiska wydzielili oni fazy funkcjonowania. Różyczanka ma 4 fazy - ,zerową" lub początkową, oraz 1, 2 i 3. Faza początkowa jest reprezentowana przez dwa pochówki. Wydzielono ją umownie dla pokazania obecności wczesnych, unikatowych dla kultury czerniachowskiej znalezisk - brązowego rzymskiego kałamarza, paciorków $\mathrm{z}$ egipskiego fajansu, miski $\mathrm{z}$ zagiętą do wewnątrz krawędzią.

Kolejną, pierwszę fazę, do której zalicza się 6 pochówków, charakteryzuje 8 wyznaczników chronologicznych. Są to sprzączki typu „omega”, wysokie otwarte misy polerowane typu „Hirka Połonka”, słabo profilowane garnki o niewielkich rozmiarach, kubki ceramiczne typu „Różyczanka”, wysokie cylindryczno-stożkowate misy, szerokie niskie misy. Wśród wskaźników synchronizacji badacze wyróżniają grzebień trapezowaty, który dla kultury czerniachowskiej jest znaleziskiem unikatowym, a także wczesny wariant fibuli z guzkiem na kabłąku oraz dzban typu zachodnioeuropejskiego.

Fazę drugą cechuje masowe pojawienie się nowych typów znalezisk, spotykanych na wielu stanowiskach czerniachowskich. Mowa tu o wykonanych z okrągłego drutu wygiętych fibulach z podwiniętą nóżką, należących do pierwszego wariantu wg A. Ambrosa, wygiętych fibulach z podwiniętą nóżką, wykonanych z półokrągłego lub trójkątnego w zarysie kawałka metalu, specyficznym zespole paciorków i zawieszek. W ceramice pojawiają się kubki, będące być może kontynuacją linii rozwojowej kubków typu „Różyczanka”, dwustożkowate misy wąskootworowe, a także żebrowane szerokie miski. W pochówkach odkrywane są trójwarstwowe kościane grzebienie o półokrągłym uchwycie.

Wskaźniki synchronizacji stanowią: sprzączka o owalnej ramie, zapinka z wysoką pochewką, dekorowana granulacją w formie kół, trzyczęściowy grzebień o trapezowatym kształcie.

Faza trzecia cechuje się wygiętymi zapinkami z podwiniętą nóżką, należącymi do trzeciego wariantu A. Ambrosa, oraz kościanymi zawieszkami w formie maczugi Heraklesa.

\footnotetext{
${ }^{23}$ Бажан, Гей 1988, 122.
} 
Za wskaźniki synchronizacji służą zapinka z podwiniętą nóżką, ornamentowana granulacją w formie kół, dwudzielna tarczowata sprzączka z ramą w kształcie litery $\mathrm{D}^{24}$.

Kosanowo. Na cmentarzysku odkryto 121 pochówków, w 33 z nich zarejestrowano datowniki. Ogółem badacze wydzielili 5 faz.

Do pierwszej fazy zaliczono, zresztą dość umownie, dwa zespoły. Charakterystyczne dla tej fazy są wygięte zapinki z podwiniętą nóżką pierwszego wariantu, sprzączka o okrągłej, cienkiej ramie, szklany żeton do gry, a także ceramiczne kubki o wyodrębnionej szyjce, zbliżone do nich pod względem formy, ale nieco większe, kubki typu „Różyczanka”.

Wskaźnikami synchronizacji są miski z pseudouchami oraz wykonane na kole półkuliste kubki.

W drugiej fazie funkcjonują kubki typu „Różyczanka”. Pojawiają się też nowe typy naczyń - duże misy $\mathrm{z}$ baniastym brzuścem, ręcznej roboty misy $\mathrm{z}$ uchami i jajowate garnki, chochle-czerpaki, dwustożkowate misy wąskootworowe. Wśród przedmiotów codziennego użytku należy wyróżnić wygięte fibule z podwiniętą nóżką, wiaderkowate zawieszki, czworograniaste paciorki z karneolu, bursztynowe zawieszki w kształcie grzyba.

Wskaźniki synchronizacji to kościany grzebień trójwarstwowy z uchwytem o zarysie wysokiego trójkąta, kubek typu „Różyczanka”, jednodzielna sprzączka kwadratowa.

$\mathrm{W}$ trzeciej fazie $\mathrm{w}$ dużej ilości zachowują się jedynie wygięte zapinki z podwiniętą nóżką, należące do 2. wariantu, wiaderkowate zawieszki oraz paciorki z karneolu. Pojawiają się zapinki Bugelknopfibeln ze spłaszczoną pochewką, a także puchary ze szlifowanymi owalami typu „Kovalk”. W ceramice występują takie formy, jak naczynia misowate $\mathrm{z}$ wygiętym wylewem, wykonany na kole garncarskim dzban o wydętym dwustożkowatym brzuścu z wyodrębnioną szyjką.

Za wskaźniki synchronizacji służą dwustożkowate naczynia z rączką, sprzączka o masywnej, owalnej ramie, trójwarstwowy grzebień o trapezowatej formie oraz paciorek ze spiralnie skręconej szklanej nici.

W fazie czwartej w użyciu pozostają przedmioty z fazy drugiej i trzeciej. Jednocześnie pojawia się cała grupa nowych typów sprzączek z owalną ramką, wygięte fibule z podwiniętą nóżką, należące do trzeciego wariantu, szklane naczynie zbliżone do typu Eggers 205, trójczęściowe grzebienie z dzwonowatym uchwytem i nacięciami na nim. W ceramice wyróżniono rozbudowane formy, takie jak kulisto-dwustożkowate misy, trójczłonowe misy z wyodrębnioną cylindryczną szyjką i dwustożkowatą częścią dolną, duże misy dwustożkowate.

W piątej fazie początkowo spotykane są jeszcze pojedyncze przedmioty $\mathrm{z}$ faz drugiej i trzeciej, później wychodzą one z użytku. Zachowuje się duża liczba arte-

\footnotetext{
${ }^{24}$ Бажан, Гей 1988, 122.
} 
faktów związanych z fazą czwartą. Pojawia się nowy typ sprzączek - o formie zbliżonej do kołacza z trąbkowatym kolcem, a także grzebieni z półokrągłym uchwytem. Wśród form ceramiki charakterystycznej dla piątej fazy należy wyróżnić szerokootworowe misy z ostrym żebrem, cylindryczne miski z przegięciem $\mathrm{w}$ dolnej części, dwa typy toczonych na kole garnków: o wydłużonych proporcjach i duże, o wypukłym brzuścu, z maksymalną wydętością w górnej części.

Wskaźniki synchronizacji to dwuuche naczynie, sprzączka, późny wariant fibuli z guzkiem na kabłąku, szklany stożkowaty pucharek zdobiony nitkami z niebieskiego szkła ${ }^{25}$.

Żurawka. Niezniszczona część cmentarzyska została całkowicie zbadana. Ogółem odkryto 125 pochówków, w tym tylko jeden ciałopalny. W opracowaniu materiałów wydzielono 5 faz funkcjonowania cmentarzyska.

Pierwsza faza charakteryzuje się dość wyraźnym zespołem ceramicznym, do którego należą kubki, misy, dwustożkowate naczynia z rączką. Wskaźnikiem synchronizacji jest szklany paciorek ze szklanego skręconego splotu.

W drugiej fazie pojawiają się ręcznie wykonane i toczone garnki, niewielkie dwustożkowate miski wąskootworowe, mające na załomie brzuśca „ścięcia" w kształcie soczewek. Wygięte zapinki z podwiniętą nóżką 1. wariantu zostają zastąpione fibulami tej samej konstrukcji, należącymi do 3. wariantu. Wskaźnikiem synchronizacji jest dzban z dwustożkowatym brzuścem.

Fazę trzecią wyznacza pojawienie się dwóch nowych form ceramiki - mis o ostrym załomie oraz mis trójdzielnych z wyodrębnioną cylindryczną szyjką i prostym wylewem. Pojawiają się też grzebienie z półokrągłym i dzwonowato ukształtowanym uchwytem. Wskaźnikiem synchronizacji jest dwuuchy dzban.

W czwartej fazie z użytku wychodzi wiele przedmiotów z faz pierwszej i drugiej. Pojawia się wiele nowych form naczyń - toczone garnki, cylidnryczno-stożkowate misy, misy o trójdzielnej budowie, a także sprzączki z ramą w kształcie wydłużonego owalu. Za wskaźnik synchronizacji służy cienkościenny puchar z przezroczystego szkła, zdobiony niebieskimi szklanymi nitkami.

Fazę piątą charakteryzuje pojawienie się zapinek o dwóch blaszkach z krótką romboidalną nóżką ${ }^{26}$.

Oseliwka. Mimo że cmentarzysko zostało w dużym stopniu zbadane, to jednak do analizy można było wykorzystać tylko 26 pochówków. W rezultacie wydzielono pięć faz funkcjonowania stanowiska.

Hawryliwka. Z 96 zbadanych pochówków do tablic korelacyjnych włączono 25. $\mathrm{Na}$ cmentarzysku wydzielono pięć faz ${ }^{27}$.

Południowy zespół zabytków (Kaborga-Kamianka). Nieliczne pochówki połączono w jedną tablicę korelacyjną, dotyczącą chronologii cmentarzysk z północ-

\footnotetext{
${ }^{25}$ Бажан, Гей 1988, 127-130.

${ }^{26}$ Бажан, Гей 1988, 140-145.

${ }^{27}$ Бажан, Гей 1988, 145-149.
} 
nego Nadczarnomorza - Kaborgi i Kamianki. Ogółem wykorzystano 17 z 22 pochówków i wydzielono 5 faz.

Dănceni. Jedno $z$ najlepiej zbadanych wykopaliskowo i przeanalizowanych cmentarzysk. Z 405 zbadanych pochówków analizie korelacyjnej poddano 34. Wydzielono $6 \mathrm{faz}^{28}$.

Fazy funkcjonowania każdego cmentarzyska zostały porównane ze sobą, i na tej podstawie opracowano fazy wspólne dla całej kultury. W rezultacie wyodrębniono 6 faz kultury rozwoju kultury czerniachowskiej i przyrównano je do chronologii bezwzględnej.

Pierwszą fazę można datować na podstawie sprzączki typu „omega”, wczesnego wariantu zapinki z guzkiem na kabłąku, okucia pasa Raddatz, fragmentu naczynia typu „Stara Zagora”. Ogólnie rzecz ujmując: cały materiał pozwala zsynchronizować tę fazę $\mathrm{z}$ fazą $\mathrm{C} 1 \mathrm{w}$ chronologii europejskiej (lata 220-260 n.e.).

Drugą fazę datują wyraźne zabytki, grzebienie o trapezowatym uchwycie, fibula z wysoką pochewką, zdobiona granulowaniem w formie kół.

Trzecią fazę wyznacza obecność monstrualnych zapinek, kulistych pucharków ornamentowanych szklaną nitką w kolorze naczynia, wczesnych egzemplarzy pucharków ze szlifowanymi owalami typu „Kovalk” oraz wielu innych zabytków, datowanych na pierwszą część fazy C2 (lata 270-300 n.e.).

Czwarta faza jest datowana obecnością: grzebieni o trójkątnym uchwycie, szklanego pucharka typu Eggers-205 i 239, grubościennego puchara ze szlifowanymi owalami typu Eggers-228. Materiał ten pozwala synchronizować dany okres z drugą połową fazy C2 (lata 300-330 n.e.).

Piąta faza datowana jest na podstawie pucharów - lampek, stożkowatych pucharów ozdobionych przyklejonymi nitkami z niebieskiego szkła, a także sprzączek z metalową nakładką typu „reńskiego”. Znaczenie dla datowania mają również szklane puchary komórkowe. Przedmioty te należy synchronizować z fazą C3 (lata 330-370 n.e.).

Szóstą fazę datują zapinki o dwóch blaszkach z romboidalną nóżką, zapinki późnego wariantu z guzkiem na cięciwie, szklana czarka ornamentowana kroplami niebieskiego szkła. Można ją synchronizować z fazą D1 (lata 370-400 n.e.) ${ }^{29}$.

Opracowując schemat chronologiczny, O. Szarow wziął pod uwagę jedynie materiały z trzech cmentarzysk: dwóch z terenu prawobrzeżnego lasostepu - Różyczanki i Kosanowa, oraz jednego z Mołdawii - Dănceni. Jako wskaźniki chronologiczne posłużyły tu, podobnie jak w przypadku innych schematów, zapinki, sprzączki, naczynia szklane i paciorki. Na ich podstawie podjęto próbę datowania ceramiki - garnków, kubków, mis.

\footnotetext{
${ }^{28}$ Бажан, Гей 1988, 128-135.

${ }^{29}$ Бажан, Гей 1988, 149-151.
} 
Badacz ten w swojej publikacji zastosował trzy podejścia. Po pierwsze, po opracowaniu typologii ceramiki porównał ją ze schematami chronologicznymi, skonstruowanymi dla całej kultury czerniachowskiej, bez zastosowania korelacji. Po drugie, dokonał wybiórczej korelacji zespołów z różnych stanowisk na podstawie oddzielnych typów ceramiki. Po trzecie, skorelował zespoły w obrębie jednego stanowiska - ceramika stanowiła tu równoprawny element całego systemu.

Podobnie jak wspomniani wcześniej I. Bażan oraz O. Hej, również O. Szarow porównał chronologię cmentarzysk Różyczanka, Kosanowo, Dănceni z systemami chronologicznymi funkcjonującymi w pozostałej części Europy. Wykorzystał przy tym prace K. Godłowskiego, E. Schallmayera, E. Kellera i J. Tejrala ${ }^{30}$.

Podczas klasyfikacji ceramiki badacz ten wybierał cztery podstawowe kategorie naczyń: garnki, kubki, misy i wysokie misy. W opracowanym przez niego schemacie widać następującą tendencję: naczynia pochodzące $\mathrm{z}$ obszaru dorzecza Bohu (Kosanowo), pogranicza Wołynia i dorzecza Bohu (Różyczanka) oraz środkowego basenu Dniestru (Dănceni) bardzo się między sobą różnią. Na podstawie analizy chronologii cmentarzysk można sądzić, że najwcześniejsze typy naczyń formują się na pograniczu Wołynia i basenu Bohu, gdzie obecne są charakterystyczne typy ceramiki, które nie występują na cmentarzyskach Dănceni i Kosanowo. Oznacza to, że nie ma ich na innych stanowiskach kultury czerniachowskiej. Region środkowego Naddniestrza również cechuje się obecnością specyficznego typu ceramiki.

Materiały z cmentarzyska Kosanowo pozwalają wnioskować, że w dorzeczu Bohu charakterystyczne formy ceramiki są reprezentowane dość szeroko. Badacz nie wyklucza ich obecności na innych stanowiskach.

Ceramika została przez O. Szarowa podzielona na cztery horyzonty chronologiczne. Do pierwszego odnoszą się jedynie materiały z Różyczanki. Ciekawa sytuacja ma miejsce $w$ horyzoncie drugim. Występuje w nim ceramika podobna zarówno do pierwszego, jak i trzeciego horyzontu. Trzeci horyzont chronologiczny charakteryzuje się większą różnorodnością form. W czwartym horyzoncie również występuje ceramika tylko dla niego charakterystyczna. Oprócz ceramiki, która odnosi się do konkretnego horyzontu, występują również formy funkcjonujące przez cały czas istnienia kultury czerniachowskiej.

Zostały zatem omówione trzy schematy chronologiczne, opracowane dla kultury czerniachowskiej. Różnią się one między sobą przede wszystkim zastosowanymi metodami i podejściem, liczbą analizowanych zabytków, wreszcie - wynikami. Najwięcej materiału przeanalizował J. Gorochowski. Ponadto, mocną stroną jego opracowania jest wykorzystanie w charakterze bazy jedynie zwartych zespołów z przynajmniej dwoma datownikami oraz podział tychże na główne i pomocnicze. Dało to badaczowi możliwość podejścia do ustalenia daty konkretnych pochówków w najbardziej wyważony sposób.

\footnotetext{
${ }^{30}$ Шаров 1988, 160-164.
} 
Zaletą badań I. Bażana i O. Hej jest próba opracowania indywidualnej periodyzacji dla każdej z wielu nekropolii, a następnie porównania ich zarówno ze sobą, jak i z ogólnoeuropejską chronologią. Jednakże niewielka liczba przeanalizowanych materiałów (tylko 10 cmentarzysk) oraz brak stopniowania wyznaczników chronologicznych negatywnie wpływają na jakość pracy i jej rezultaty.

Podstawowym celem opracowania O. Szarowa było datowanie ceramiki. Naczynia gliniane i ich fragmenty stanowią najbardziej masowy materiał, a zatem udane opracowanie ich chronologii umożliwiłoby rozstrzygnięcie wielu problemów. Jednak ograniczona pula wykorzystanego materiału (praktycznie tylko dwa cmentarzyska) nasuwa wątpliwości co do wiarygodności wniosków wspomnianego autora.

A zatem najbardziej przydatne w datowaniu stanowisk i zespołów kultury czerniachowskiej jest najprawdopodobniej opracowanie J. Gorochowskiego.

Kolejną ważną kwestią są ramy chronologiczne wczesnego etapu kultury czerniachowskiej, a dokładniej - początek jej formowania. Jak już wspomniano, J. Gorochowski do wczesnego etapu odnosi zespoły fazy „różyczańskiej” i datuje je na lata 230-270 n.e. I. Bażan i O. Hej synchronizują tę fazę z fazą C1 ogólnoeuropejskiej chronologii (lata 220-260 n.e.).

O. Szarow datuje wczesną fazę na lata 238-275 n.e., synchronizując ją z europejskim schematem chronologicznym opracowanym dla okresu wpływów rzymskich. Uważa on, że wczesna faza kultury czerniachowskiej jest współczesna fazie $\mathrm{C} 1 \mathrm{~b}-\mathrm{C} 2^{31}$.

Jedynie M. Szczukin ostrożnie zauważa, iż początki kształtowania się kultury czerniachowskiej mogły przypaść na przełom II-III w. n.e. ${ }^{32}$.

Omówione prace odnoszą się głównie do chronologii stanowisk. Najbardziej przydatne w opracowywaniu takich schematów są zespoły zwarte. Są to przede wszystkim pochówki. Charakterystyka jakiegokolwiek okresu nie będzie jednak pełna, jeśli nie zostaną wzięte pod uwagę materiały z osad. B. Magomedow do wczesnego etapu zalicza niektóre horyzonty stan. Ripniw, Czerepin, Nesłuchiw oraz Lepesiwka $^{33}$. A zatem, omówiwszy pokrótce historię badań wczesnych stanowisk kultury czerniachowskiej, można stwierdzić, co następuje:

1. Mimo że wczesne stanowiska czerniachowskie znane są od ostatniej ćwierci XIX w., do tej pory faza wczesna nie była rozpatrywana osobno.

2. Pojedyncze wczesne zespoły analizowano jedynie z perspektywy badań nad chronologią.

3. Obecnie znane są trzy schematy chronologiczne kultury czerniachowskiej:

- J. Gorochowskiego

- I. Bażana i O. Hej

- O. Szarowa.

\footnotetext{
${ }^{31}$ Шаров 1988, 190-194.

${ }^{32}$ Щукин 1999, 16-19, rус. 5.

${ }^{33}$ Магомедов 2001, ryc. 88.
} 
Różnią się one zarówno podejściem, jak i rezultatami. Najbardziej optymalne jest, jak się wydaje, datowanie opracowane przez J. Gorochowskiego. Aktualna zatem pozostaje kwestia badań wczesnego etapu kultury czerniachowskiej, który do tej pory nie był szczegółowo rozpatrywany. Dokładne studia nad tymże etapem dałyby możliwość rozstrzygnięcia wielu ważnych i dyskusyjnych dla czerniachowskiej kultury pytań badawczych.

\section{BIBLIOGRAFIA}

Амброз А.К.

1966 Фибуль юга европейской части СССР II в. до н. э.- IV в. н. э. [w:] ред. Ю.В. Кухаренко, Свод археологических источников Д1-30, Москва.

Баран В.Д.

1961 Поселення перших століть нашої ери біля села Черепин, Київ.

1964 Памятники черняховской культуры бассейна Западного Буга (раскопки 1957-1960 гг.), Материалы и исследования по археологии 116, s. 213-250.

Бажан И.А., Гей О.А.

1992 Относительная хронология могильников черняховской культуры [w:] Проблемы хронологии эпохи латэна и римского времени. По материалам первых Тихановских чтений. Ленинград, 1988 г., ред. В.Е. Ероменко, Санкт-Петербург, s. 128-149.

Винокур И.С., Островский М.И.

1967 Раковецкий могильник, Материаль и исследования по археологии 139, s. 144-159. Винокур И.С.

1979 Ружичанский могильник [w:] Могильники черняховской культуры, ред. Э.А. Сымонович, Москва, s.112-135.

Гороховский Е.Л.

1988 Хронология черняховских могильников Лесостепи Украины [w:] Tpyды V Mеждународного конгресса археологов-славистов IV, s. 34-46.

Герета І.П.

1991 Розкопки черняхівського могильника в Чернелеві-Руському [w:] Нові матеріали з археології Прикарпаття і Волині, ред. В.П. Лагодзька, Львів, s. 54-56.

1995 Нові пам'ятки Західного Поділля в світлі проблем черняхівської культури, Матеріали досліджень археології Прикарпаття і Волині 6, s. 144-163.

Гавритухин И.

1999 Хронологические индикаторы финала черняховской куьтуры [w:] Cmo лет черняховской культуре, ред. М.Е. Левада, Киев, s. 48-86.

Кравченко Н.М.

1967 Косановский могильник (за материалами раскопок В.П. Петрова и Н.М. Кравченко в 1961-1964 гг.), Материаль и исследования по археологии 139, s. 77-135. Кропоткин В.В.

1972 Золотая подвеска из Рыжевки, Советская археология 1, s. 264-269.

Кухаренко Ю.В.

1955 Поселение и могильник полей погребений в с. Привольное, Советская археология XXII, s. 125-152. 


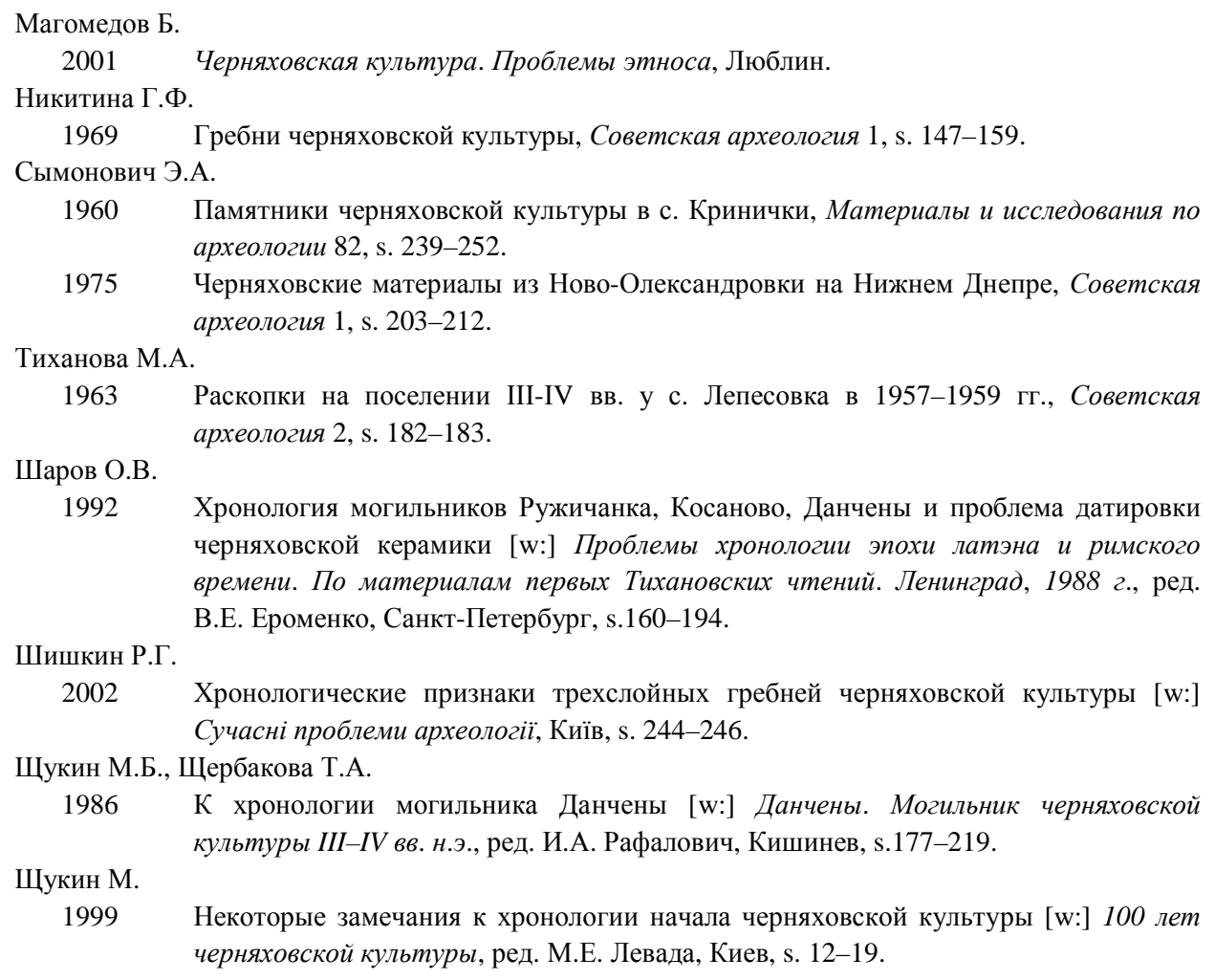

\section{HISTORY OF RESEARCH ON THE SITES OF EARLY CHERNYAKHOV CULTURE}

\section{S u m m a r y}

The article disscuses three chronological schemes of the Chernyakhov culture, provided by J. Gorochovskij, by I. Bazhan and O. Hey, and by O. Sharov. They differ from one another mainly in terms of methods applied and an approach, number of artefacts analysed, and finally also in results achieved. The greatest number of data has been analysed by Gorochovskij, who, in his study, considered only assemblages which had at least two chronological indicators, divided by him into main and supportive ones. It allowed for most accurate dating of each burial.

Bazhan and Hey attempted to develop individual periodization of each of several necropolises and then to compare them, both - to one other, and to other ones within the frame of the European chronology. Unfortunately, limited number of cemeteries taken into consideration (only ten), as well as the lack of reliable chronological indicators have made the results of the study less valuable. 
The main aim of Sharov's study was to provide dating of pottery. Clay vessels and potsherds have represented the most numerous group o artefacts, thus working out their chronology would help to solve several problems. However, as there were only two cemeteries taken into consideration, the study appears less reliable.

Different dates of the periods resulted from various approaches of the researchers.

Translated by Karolina Harat 